\title{
Pulmonary vascular and alveolar development in tetralogy of Fallot: a recommendation for early correction
}

\author{
RJ JOHNSON, SHEILA G HAWORTH
}

From the Department of Paediatric Cardiology, Institute of Child Health, London

ABSTRACT Using quantitative morphometric techniques, we analysed pulmonary arterial and alveolar development in the lungs of seven children aged 1·2-12 years who died during or soon after repair of tetralogy of Fallot. One child had a residual ventricular septal defect and survived for five months. One other child had had a previous Waterston-Cooley anastomosis (Waterston shunt). Postmortem lung volume in relation to body surface area was generally below normal for age, the alveoli were small, and the total alveolar number was below normal in five of the seven cases. Microscopically, airway and alveolar structure appeared normal. The preacinar arteries were larger and the intra-acinar arteries were smaller than normal for age. The preacinar elastic pulmonary arteries appeared to contain less elastin and in both preacinar and intra-acinar muscular arteries the media was thinner than normal, although muscle was normally distributed along the arterial pathway. Eccentric areas of intimal fibrosis were small and uncommon. The bronchial arteries were generally more prominent than usual both macroscopically and microscopically, but no abnormal bronchopulmonary connections were present. After corrective surgery a residual ventricular septal defect and pulmonary hypertension were associated with arterial medial hypertrophy, and this change was also found in the right lung of a normotensive patient who had had a Waterston shunt. This group probably represents the most favourable clinical picture of tetralogy in patients who usually survive but, even so, pulmonary arterial and alveolar development was abnormal. The structural findings are discussed in relation to the functional outcome in patients with tetralogy who have survived. Repair of the abnormality during the first two to three years of life is recommended.

For most patients with tetralogy of Fallot the prognosis is good. The five-year survival of patients who have had a Blalock-Taussig anastomosis followed by "corrective" surgery is $85 \%$ and many children undergo elective repair without having needed palliative surgery.' In such patients the extrapulmonary arteries are not appreciably hypoplastic, but within the lung the state of development of the pulmonary circulation is uncertain. At corrective surgery, however, the ability of the lung to accommodate an increase in blood flow satisfactorily depends on the capacity of the pulmonary circulation. In adult life the structure and function of the lung is probably related to the state of

Address for reprint requests: Dr SG Haworth, Department of Paediatric Cardiology, Hospital for Sick Children, Great Ormond Street, London WC1N 3JH pulmonary vascular development at the time of corrective surgery. Previous studies on the structure of the pulmonary vasculature have given conflicting results, probably because of the variation in the clinical picture and in the age of the patients studied. ${ }^{2-8}$

In the present study pulmonary vascular and alveolar development have been analysed in the lungs of seven children who died during or soon after corrective surgery. Six patients had not required palliative surgery and they probably represent the most favourable clinical picture of tetralogy in patients who usually survive.

\section{Patients and methods}

THE PATIENTS

Seven patients aged $1 \cdot 2-12$ years died after surgical 
repair of tetralogy of Fallot (table 1). In one child (case 7) a Waterston shunt had been performed at $2 \frac{1}{2}$ years of age. None of the other patients had had palliative surgical treatment and they will therefore be described as untreated. All were on or below the 10th centile for height except for one child (case 7), who was on the 50th centile. All patients had reduced exercise tolerance and all but one (case 5) were cyanosed.

In all patients the preoperative chest radiograph showed a heart of normal size (cardiothoracic ratio $0.43-0.52$ ), with a reduction in peripheral pulmonary vascular markings. On pulmonary angiography the extrapulmonary, hilar, lobar, and segmental arteries appeared to be of normal size, although the peripheral branches were smaller than normal (fig 1).

Five patients died during or within 12 hours of surgery, four with bleeding problems. In cases 5 and 6

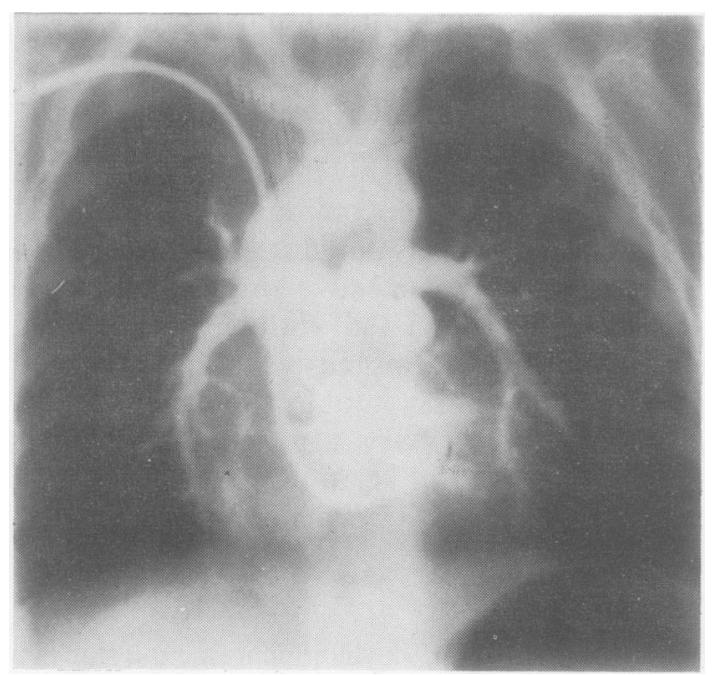

Fig 1 Pulmonary angiogram (case 2) showing hilar and lobar arteries of normal size and smaller peripheral arteries. there was a residual ventricular septal defect and these children died 10 days and five months after the operation.

\section{PREPARATION OF LUNG TISSUE AND}

MORPHOLOGICAL ANALYSIS

At necropsy the pulmonary arteries were injected with a barium sulphate and gelatin mixture at $60^{\circ} \mathrm{C}$ and a pressure of $75.6 \mathrm{~mm} \mathrm{Hg} .^{.10}$ The lungs were fixed by injecting the airways with formol saline at a pressure of $45 \mathrm{~cm} \mathrm{H}_{2} \mathrm{O}$. The volume of each fixed lung was determined by water displacement.

On a postmortem arteriogram the length of the posterobasal artery from the hilum to the pleural surface was measured, and the lumen diameter' was $ᄋ$ measured at the hilum and at $25 \%$ intervals along the pathway. Most of the children were smaller than normal for their age, and to compensate for this the lumen diameter at each position in each lung was related to the total length of the pathway and this ratio compared with that found in controls of similar age, Student's paired $t$ test being used. For the group, to determine the percentage change from normal an analysis of variance was carried out by comparing the lumen diameter at each position with the normal for age, the total pathway length being used as the covariate.

To determine the number of alveoli in the lung the volume proportion of lung parenchyma was determined by a point-counting technique. ${ }^{11}$ Blocks of tissue were selected for histological preparation by a randomised sampling technique. Sections of tissue were stained with haematoxylin and eosin and with Miller's elastic stain counterstained with van Gieson's stain.

\section{MICROSCOPIC STUDIES}

The structure of the elastic pulmonary arteries was examined at hilar and lobar level in six cases. The number of elastic laminae was determined at three points around the circumference of each vessel by the

Table 1 Clinical data on the seven cases of tetralogy of Fallot

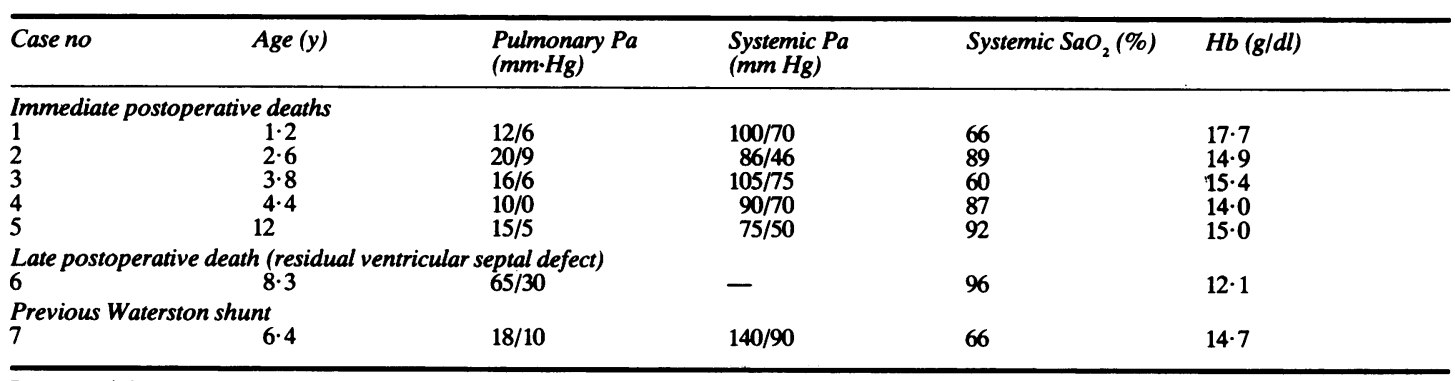

$\mathrm{Pa}$-arterial pressure; $\mathrm{SaO}_{2}$-arterial oxygen saturation. 
linear intercept technique and the mean number of elastic laminae was calculated. In each peripheral pulmonary artery examined the external diameter and medial wall thickness were measured. Percentage medial thickness was calculated as $(2 \times$ medial wall thickness) $\div$ external diameter $\times 100$. Arteries were grouped into size ranges, with external diameters of 0-25, 26-50, 51-75, 76-100, 101-200, 201-300, 301$400,401-500,501-1000$, and greater than $1000 \mu \mathrm{m}$. For each size range mean percentage arterial thickness and the standard error of the mean were calculated.

Intra-acinar arteries were identified according to the type of peripheral airway they accompanied. The external diameter of arteries accompanying terminal and respiratory bronchioli, alveolar ducts, and alveolar walls was measured and the mean external diameter was calculated for each airway level. The proportions of muscular, partially muscular, and nonmuscular arteries at each airway level were also determined.

In each lung a population count was done by measuring the external diameter and determining the wall structure (muscular, partially muscular, or nonmuscular) of all the intra-acinar arteries in each section of tissue examined. For each lung the median external diameter of the partially muscular arteries was calculated. To determine how far along the pathway muscle extended the median external diameter of the partially muscular arteries was compared with the mean external diameter of arteries accompanying respiratory bronchioli and alveolar ducts in each lung.

The numbers of arteries and alveoli lying within the same microscopic field were counted. In each specimen a minimum of 25 fields was examined. The ratio of alveoli to arteries was used to assess arterial number in order to compensate for differences in the degree of inflation. The microscopic volume proportion of alveolar air space was determined. The number of alveoli per cubic centimetre and the total number of alveoli in the lung were calculated with the formula derived by Dunnill ${ }^{11}$ :

$$
N=\frac{n^{3 / 2}}{\beta \sqrt{p}} \times P \times V,
$$

where $N=$ total alveolar number, $n=$ number of alveoli per $\mathrm{cm}^{2}, P=$ volume proportion of parenchyma, $\boldsymbol{p}=$ volume proportion of alveolar air, $V=$ lung volume, $\beta=$ alveolar shape constant of $1 \cdot 55$.

In each case the findings on the postmortem arteriogram; the results of the microscopic analysis of arterial muscularity, size, and number; and the alveolar number were compared with published findings in a child of similar age. ${ }^{12}$ The difference in age between the four youngest patients and the controls was less than three months and for the older children the difference was between one and two years. The control lung specimens had been examined by exactly the same methods as in the present study and were obtained from children who had died accidentally.

\section{Results}

\section{LUNG VOLUME AND NUMBERS OF ALVEOLI}

In all the cases examined lung volume was smaller than normal with respect to both age and body surface area (table 2). The mean lung volume was $75 \%$ of normal for age. In all cases the number of alveoli per cubic centimetre was greater than normal with respect to both age and body surface area. The total number of alveoli in each lung examined was normal in only two children (cases 1 and 7) and reduced in the other five cases. Thus despite an

Table 2 Lung volume and numbers of alveoli in the cases of tetralogy of Fallot (normal values for age in parentheses)

\begin{tabular}{|c|c|c|c|c|c|c|c|}
\hline Case No & Age (y) & $\begin{array}{l}\text { Body surface } \\
\text { area }\left(m^{2}\right)\end{array}$ & $\begin{array}{l}\text { Lung } \\
\text { examined }\end{array}$ & $\begin{array}{l}\text { Lung } \\
\text { volume* }\end{array}$ & $\begin{array}{l}\text { Alveoli per } \\
\mathrm{cm}^{3} \times 10^{3} \dagger\end{array}$ & $\begin{array}{l}\text { Total No of alveoli } \\
\times 10^{6}+\end{array}$ & $\begin{array}{l}\text { Alveolar: } \\
\text { arterial ratio }\end{array}$ \\
\hline 1 & $1 \cdot 2$ & $0 \cdot 38(5)$ & $\begin{array}{l}\text { Right } \\
\text { Left }\end{array}$ & $\begin{array}{l}160(285) \\
158(280)\end{array}$ & $\begin{array}{l}1080(284) \\
1100(284)\end{array}$ & $\begin{array}{l}174(143) \\
174(143)\end{array}$ & $\begin{array}{l}8 \cdot 2 \\
8 \cdot 4\end{array}$ \\
\hline 2 & $2 \cdot 6$ & $0.42(2.5)$ & Left & - & - & - & $4 \cdot 8$ \\
\hline 3 & $3 \cdot 8$ & $0.51(2 \cdot 5)$ & $\begin{array}{l}\text { Right } \\
\text { Left }\end{array}$ & $\begin{array}{l}342(380) \\
287(300)\end{array}$ & $\begin{array}{l}518(367) \\
667(367)\end{array}$ & $\begin{array}{l}178(252) \\
192(252)\end{array}$ & $\begin{array}{l}8 \cdot 0 \\
8.5\end{array}$ \\
\hline 4 & $4 \cdot 4$ & $0.56(2 \cdot 5)$ & Right & $295(380)$ & $\begin{array}{l}623(367) \\
621(367)\end{array}$ & $184(252)$ & 5.5 \\
\hline $\begin{array}{l}5 \\
6 \\
7\end{array}$ & $\begin{array}{l}12 \\
8 \cdot 3 \\
6 \cdot 4\end{array}$ & $\begin{array}{l}0 \cdot 99(2.5) \\
0 \cdot 82(10) \\
0.92(50)\end{array}$ & $\begin{array}{l}\text { Left } \\
\text { Left } \\
\text { Right } \\
\text { Left }\end{array}$ & $\begin{array}{l}\frac{100}{388(1065)} \\
329(1185) \\
319(1180)\end{array}$ & $\begin{array}{l}-509(243) \\
895(367-243) \\
732(367-243)\end{array}$ & $\begin{array}{l}\overline{1} \\
197(290) \\
294(252-290) \\
233(252-290)\end{array}$ & $\begin{array}{c}0 \cdot 5 \\
8 \cdot 6 \\
6 \cdot 9 \\
8 \cdot 0 \\
10 \cdot 5 \\
(8-10 \dagger)\end{array}$ \\
\hline
\end{tabular}

${ }^{*}$ Normal values from Hislop ${ }^{12}$ in parentheses.

$\dagger$ Normal values derived from Dunnill " in parentheses. 
increase in the density of alveoli the reduction in lung volume led to a reduction in the total alveolar number in most cases.

\section{ARTERIOGRAMS}

In all seven cases the pulmonary arterial branching pattern was normal and there were no stenoses. By comparison with age-matched controls, the lumen diameter of the preacinar arteries was increased along the entire length of the pathway in all specimens except the left lung in case 7 , where it was normal. In addition, the lumen diameter related to total pathway length at each position between the hilum and the pleural surface was greater than that in age-matched controls in all cases (fig 2), and for the group the increase was statistically significant at the $25 \%$ position $(p<0.05)$ (fig 3$)$. In the child (case 7) who had had a Waterston shunt, along the proximal $60 \%$ of the arterial pathway the lumen diameter was greater in the right than in the left lung but more distally the lumen diameter was less in the right than in the left lung. The difference in the gradient of the lumen diameter between hilum and pleural surface in the two lungs was significantly different $(p<0.01)$. The bronchial arteries filled with the injection medium and were larger than normal in five of the seven cases.

\section{MICROSCOPIC FINDINGS}

In all cases the airways and alveoli had a normal appearance. The small preacinar arteries appeared dilated by comparison with the accompanying airway. These vessels also branched more frequently and at a more obtuse angle than is seen in the normal lung (fig 4). The bronchial arteries running with the large airways were distended with the injection medium to a greater extent than is normal and they appeared larger than normal in four cases. Bronchopulmonary anastomoses (the connections between large bronchial arteries and adjacent thinwalled arteries of the alveolar ducts and alveolar walls ${ }^{13}$ ) were more prominent and larger than in the normal lung. On serial sectioning, bronchial arteries were traced to the necks of the terminal and respiratory bronchioli, where they merged with thinwalled alveolar duct and alveolar wall arteries, as is normal. Both the preacinar and the intra-acinar arteries appeared to be abnormally thin walled.

\section{APPEARANCE OF HILAR AND LOBAR ELASTIC INTRAPULMONARY ARTERIES}

By definition, in the normal lung an elastic artery is composed of seven or more concentric elastic laminae with muscle cells and collagen lying between the

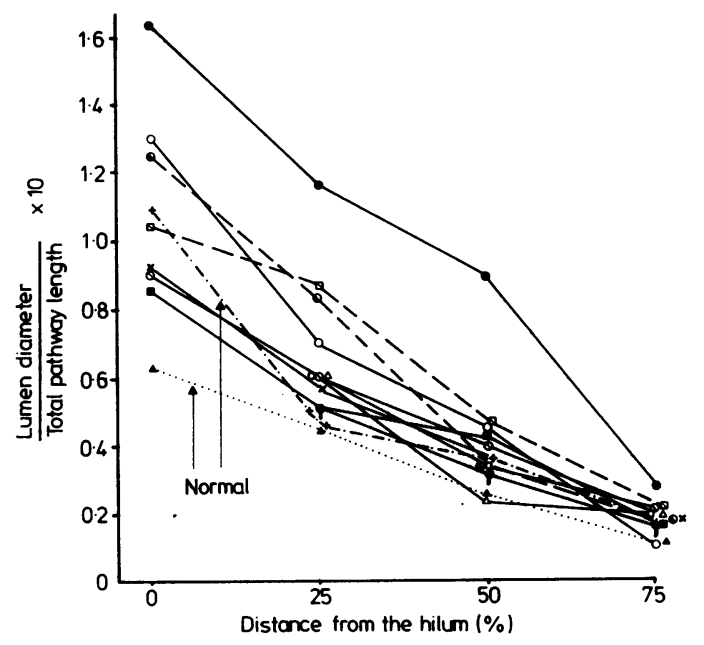

Fig 2 Relation of lumen diameter to total length of arterial pathway: (lumen diameter $\div$ total pathway length) $\times 10$, determined at intervals along the arterial pathway in specimens from all seven cases (except the left lung in case 7), compared with the normal values for the youngest

(A- - - A) and oldest patient $(+-\cdot-+)$.
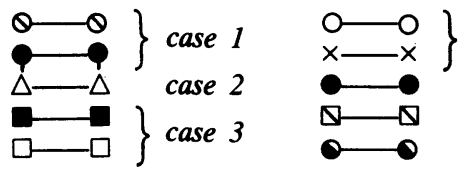

case 4
case 5
case 6
case 7 (right lung).

elastic fibres. ${ }^{14}$ In five of the six cases of tetralogy in which elastic wall structure was examined, the arteries near the hilum contained fewer elastic laminae than is usual at the hilum-from six to nine. The lobar arteries contained five or six elastic $\frac{0}{\partial}$ laminae. In case 1 , the exception, the right pulmonary artery contained 20 elastic laminae. Thus $\delta$ in most cases the hilar arteries just fulfilled the criteria of an elastic artery, and the proximal region of the 웅 lobar arteries had the structure of transitional $D$ arteries, normally present at a more distal point along the arterial pathway, midway between hilum and $\bar{N}$ pleural surface. Furthermore, the elastic fibres were 0 thinner and more fragmented than normal and there were fewer interlamellar thin elastic fibres than $\underset{\omega}{N}$ normal, particularly in cases 2,3 , and 4 .

In case 7 , where there had been a Waterston anastomosis, the elastic pulmonary arteries in the left lung were thin walled, as in the other cases of ? tetralogy, but were thicker in the right lung (fig 5). 0 The pulmonary artery of the right lower lobe was composed of only six elastic laminae; but it contained a greater amount of muscle between the laminae than $\stackrel{\mathbb{D}}{\mathrm{D}}$ did the same vessel in other cases, and the interlamellar distance was greater. 


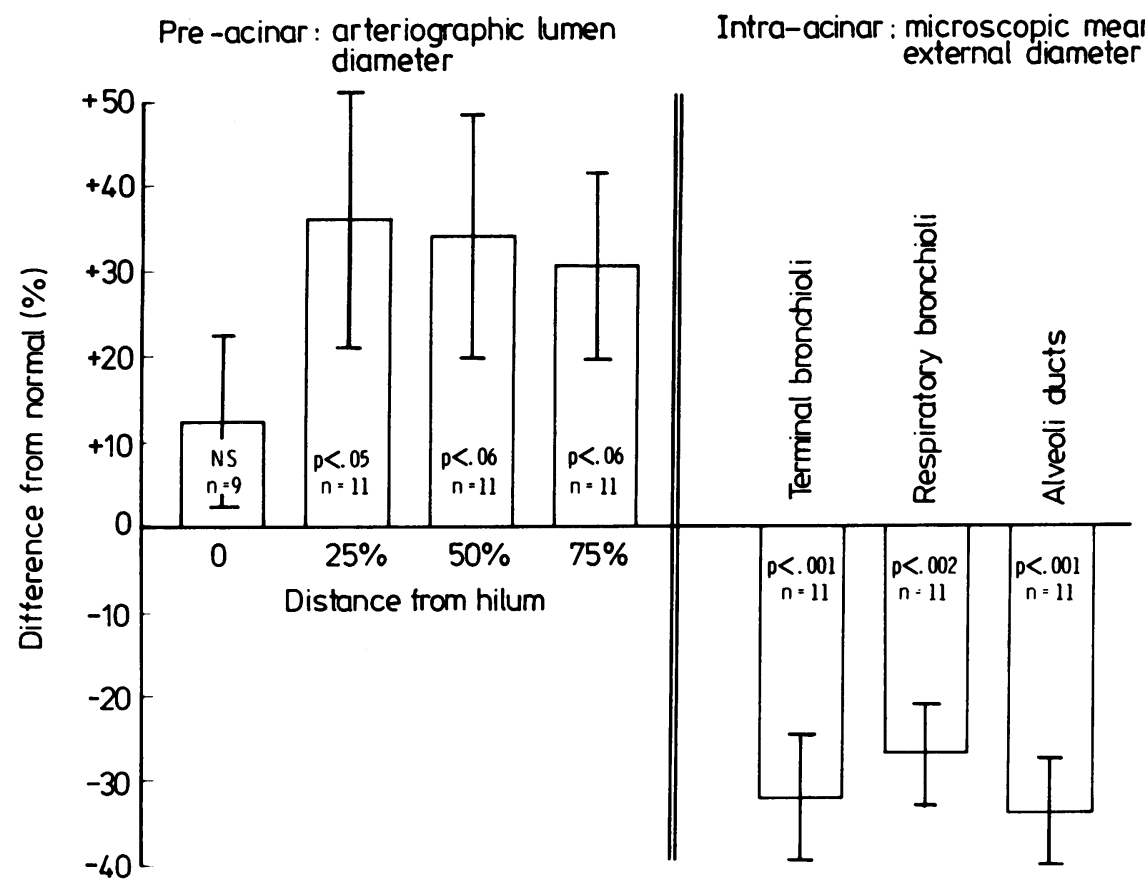

Fig 3 Comparison of preacinar and intra-acinar arterial size in seven cases of tetralogy (11 lung specimens) with the values for age-matched normal controls. For the group the lumen diameter of the preacinar arteries in relation to total pathway length was greater and the mean external diameter of the intra-acinar arteries was less than normal for age. Vertical bars represent the standard error.

\section{INTIMAL CHANGE}

Intimal changes were neither severe nor widespread. None were found in the lungs of the two youngest patients (cases 1 and 2). In the remaining five cases only small eccentric plaques of intimal fibrosis were present in a minority of small preacinar, terminal, and respiratory bronchiolar and alveolar duct arteries. The child who died with a residual

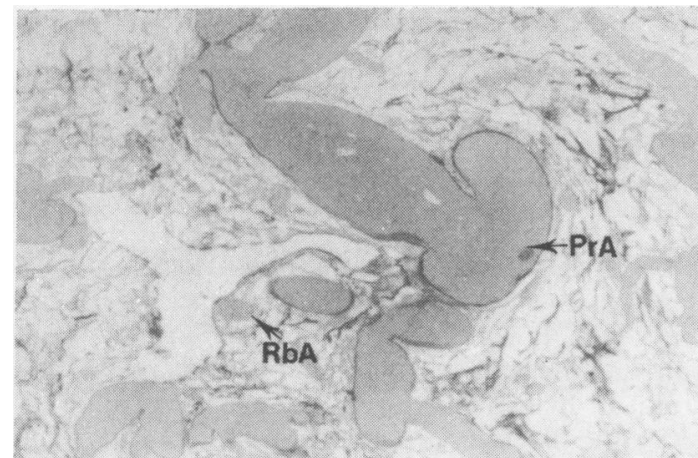

Fig 4 Dilated thin-walled preacinar and small intra-acinar arteries. PrA-preacinar artery; RbA-respiratory bronchiolar artery. $(\times 62$. ventricular septal defect (case 6) showed the greatest intimal changes, but they were not severe.

\section{QUANTITATIVE ASSESSMENT}

\section{Arterial muscularity}

The mean percentage arterial medial thickness of the eight lung specimens analysed in cases 1-5 was significantly less than normal (fig 6). In only two of these specimens was muscularity normal, and in both instances it was significantly reduced in the contralateral lung. Of the two remaining patients, muscularity was significantly increased in the child who died with a residual ventricular septal defect and pulmonary hypertension (case 6), and in the right lung of the child who had had a Waterston shunt (case 7). In this case in the left lung muscularity was significantly reduced as in the other cases of tetralogy.

Comparison of the median external diameter of the partially muscular arteries with the mean external diameter of arteries accompanying peripheral airways showed that in all except two cases muscle extended as far along the arterial pathway as is normal in relation to age-namely, to alveolar duct level. Muscle extended further than normal along the 


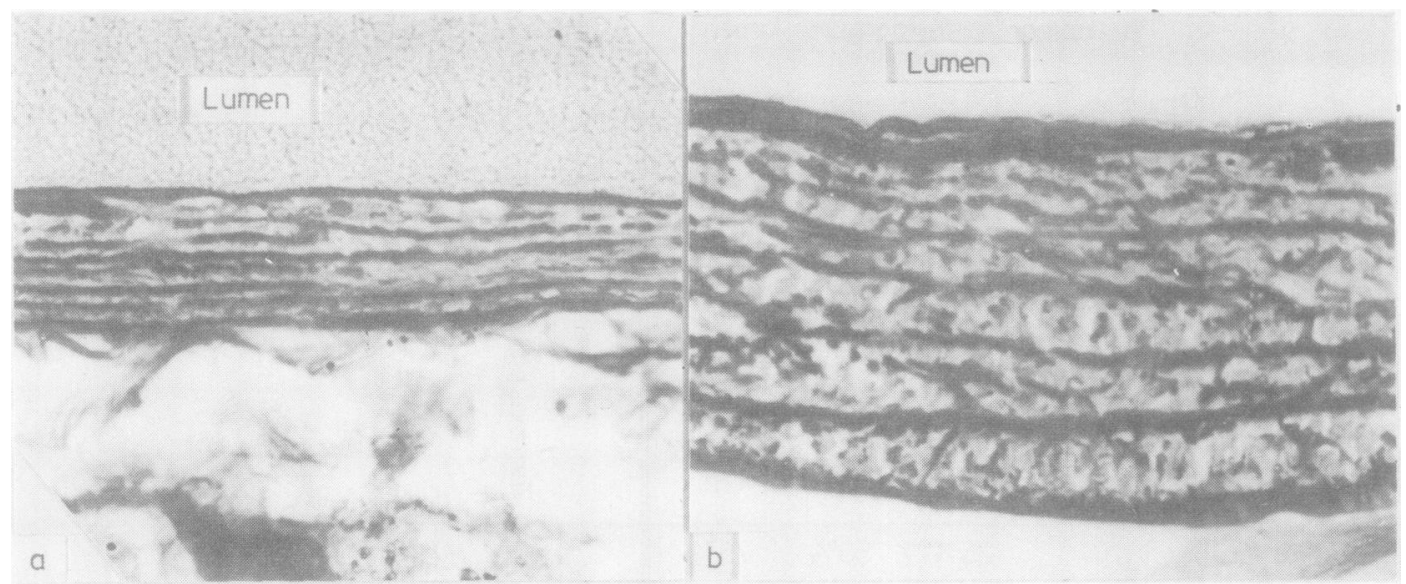

Fig 5 Large elastic pulmonary artery from (a) the left lung and (b) the right lung of the child (case 7) who had had a Waterston-Cooley anastomosis, showing the greater wall thickness of the right intrapulmonary arteries. $(\times 450$.

pathway into smaller, more peripheral arteries in case 6 (pulmonary hypertension) and in the right lung in case 7 (Waterston shunt).

Fig 6 shows that muscle is present in smaller arteries than normal in children who had a reduction in relative medial thickness. Examination of the size and structure of arteries accompanying peripheral airways shows that this is because the arteries are smaller than normal.

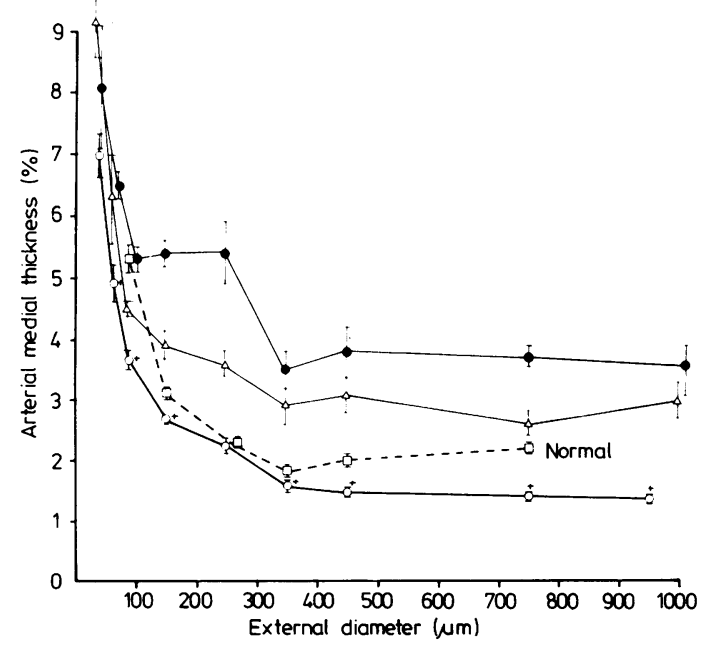

Fig 6 Mean percentage arterial medial thickness in relation to external diameter $(\mu \mathrm{m})$ in cases of tetralogy compared with normal. Cases $1-5$ and left lung of case $7 \bigcirc-O$; case $6 \triangle \longrightarrow \triangle$; case 7 right lung - - normal $\square-.--\square$. The vertical bars represent the standard error. + Significant difference from normal $(p<0.05)$.

\section{Intra-acinar arterial size}

Unlike the preacinar arteries seen on the arteriograms the intra-acinar arteries were smaller than normal in five of the seven cases. For the group of seven cases the mean external diameter of arteries accompanying terminal and respiratory bronchioli and alveolar ducts was significantly below the normal mean size for age $(p<0 \cdot 01-0.001)($ fig 3$)$. There was no tendency for size to decrease further from normal with increasing age. Intra-acinar arterial size was normal in cases 5 and 6 . In the four cases in which a comparison between the right and left lung could be made the arteries were of similar size in both lungs, and this includes the case (no 7) in which there had been a Waterston-Cooley anastomosis.

\section{Number of intra-acinar arteries}

On the postmortem arteriograms an increase in the density of the background haze in all except that of case 6 suggested an increase in the number of intraacinar arteries. This was confirmed by counting the number of arteries and alveoli per unit area of lung. The alveolar:arterial ratio was below normal in three cases and at the lower limit of normal in all the remaining specimens except the left lung in case 7 (table 2).

\section{SUMMARY OF PATHOLOGICAL FINDINGS}

Lung volume related to body surface area was generally below normal for age, the alveoli were small, and the total alveolar number was smaller than normal in five of the seven cases. Microscopically, airway and alveolar structure appeared normal. The preacinar arteries were larger and the intra-acinar arteries were smaller than normal for age. The preacinar elastic pulmonary arteries appeared to 
contain less elastin and in both preacinar and intraacinar muscular arteries the media was thinner than normal, although muscle was normally distributed along the arterial pathway. Eccentric areas of intimal fibrosis were small and uncommon. The bronchial arteries were generally more prominent than usual both macroscopically and microscopically, but no abnormal bronchopulmonary connections were present. After corrective surgery a residual ventricular septal defect with pulmonary hypertension was associated with arterial medial hypertrophy, and this change was also found in the right lung of a normotensive patient who had had a Waterston shunt.

\section{Discussion}

In patients with tetralogy of Fallot who have not undergone previous palliative surgery the findings in the present study suggest that after an intracardiac repair an increased volume of blood is ejected into large, distensible preacinar arteries which branch into an increased number of small, thin-walled intraacinar arteries. Although these structural abnormalities must alter the flow profile, they would seem unlikely to increase resistance to flow. These observations support the favourable clinical reports of cardiovascular function after repair. The absence of pulmonary hypertension in 101 patients investigated by Gotsman $e a^{15}$ and by Epstein et al ${ }^{16}$ attests to the capacity of the pulmonary vascular bed.

In the present series, pulmonary angiography in life showed hilar, lobar, and segmental arteries of at least normal size and postmortem arteriography showed these arteries to be dilated. The small preacinar arteries were also dilated on microscopic examination. Arterial dilatation was also found by Wagenvoort et $a l^{7}{ }^{17}$ but the finding is not readily explained. In the present study the increase in size on the postmortem arteriogram cannot be attributed to the injection technique since Hislop and Reid ${ }^{8}$ used the same technique and showed a reduction in arterial size in a group of patients with tetralogy. Arterial dilatation might, however, be due to structural changes in the intrapulmonary arteries. In the present series the walls of both elastic and muscular preacinar arteries were thin and in the elastic arteries the elastic fibres were less dense and less compactly arranged than is normal. Other studies have also shown a reduction in the amount of elastin, assessed both histologically and biochemically, in patients with tetralogy. ${ }^{18}$ Such changes probably increase the distensibility of a vessel wall.

Unlike the preacinar arteries, within the acinus the arteries were significantly smaller than normal. With the same quantitative techniques a reduction in intra- acinar arterial size has been reported in other patients with tetralogy ${ }^{8}$ and in other conditions of reduced pulmonary blood flow. ${ }^{519} 20$ In pulmonary atresia with an intact ventricular septum the intra-acinar arteries are abnormally small at birth. ${ }^{519}$ In patients with pulmonary atresia and major aortopulmonary collateral arteries the intra-acinar arteries in bronchopulmonary segments perfused by small collateral arteries are also smaller than normal for age. ${ }^{20}$ Thus there appears to be a critical level of pulmonary arterial pressure or blood flow, or both, that is required to ensure normal development of the intra-acinar arteries.

Although the intra-acinar arteries were small in several cases they were increased in number. An increased number of intra-acinar arteries has been reported in other cases of tetralogy. ${ }^{8}$ On the postmortem arteriogram the increased density of the background haze, the moss-like appearance, ${ }^{7}$ can be attributed both to the dilatation of small preacinar arteries and to the increase in number of small intraacinar arteries.

In the small preacinar arteries and in the intraacinar arteries the media was thinner than normal in all untreated patients dying at surgery. Previous studies have given conflicting results. Wagenvoort and Edwards ${ }^{6}$ reported a reduction in muscularity, while others have found a normal ${ }^{23}$ or even an increased wall thickness. ${ }^{8}$ The thin medial coat is frequently said to be atrophied in tetralogy, but this seems unlikely since atrophy implies a reduction in muscularity, and muscularity is probably never normal in postnatal life in patients with tetralogy of Fallot. Indeed babies with pulmonary atresia and intact ventricular septum are born with abnormally thin-walled arteries. ${ }^{519}$ Despite the thinness of the media, however, it hypertrophies in response to an increase in pressure, or flow, as was seen after a Waterston-Cooley anastomosis had been performed and in the child with a residual postoperative ventricular septal defect. Recent experimental studies have shown that in pulmonary hypertension smooth muscle cells increase in size rather than in number. ${ }^{21}$ The ability of the medial coat to hypertrophy in tetralogy of Fallot suggests that the children are probably born with a normal number of abnormally small smooth muscle cells in the media. Supporting this hypothesis is the observation that in children with tetralogy muscle cells extend as far down the arterial pathway as in the normal child.

The thin-walled, small intra-acinar arteries may help to explain why after a repair a residual ventricular septal defect may be more hazardous than in a patient with an isolated ventricular defect. Clinically such patients may be difficult to manage, and at necropsy the capillaries are engorged with 
blood. The structurally abnormal pulmonary vascular bed may not accommodate the volume of blood flowing through the residual ventricular septal defect without difficulty.

The potential complications of shunt procedures are well recognised. ${ }^{22}{ }^{23}$ In case 7 in the present study the child had had a good shunt in that he improved clinically and did not develop pulmonary hypertension. Alveolar development was similar in the two lungs but unequal perfusion is suggested by the greater preacinar arterial size and the greater wall thickness of the preacinar and intra-acinar arteries in the right than in the left lung. Radionuclide studies after corrective surgery showed relative hypoperfusion of the lung which had received the shunt, resulting in ventilation-perfusion imbalance. ${ }^{24}$

In the past the absence of postoperative pulmonary hypertension has been attributed to a reserve capacity of the pulmonary vascular bed sufficient to compensate for the reduction in cross-sectional area caused by thrombosis and intimal change. Such severe change was, however, absent in the present series and is probably unusual nowadays with earlier palliative and corrective surgery. Intimal thrombosis has been attributed to a low systemic arterial oxygen saturation (less than $60 \%$ ), polycythaemia, a low pulmonary blood flow, or a combination of these features. ${ }^{22} 25$ We found mild intimal change, however, despite a systemic arterial oxygen saturation greater than $60 \%$, a haemoglobin concentration of $15.4 \mathrm{~g} / \mathrm{dl}$ or less, and in one patient a satisfactory pulmonary blood flow after a Waterston-Cooley anastomosis. Whatever the aetiology of intimal thrombosis, in our patients with a typical and favourable clinical picture of tetralogy pulmonary vascular thrombosis could not have caused postoperative pulmonary hypertension.

In several cases the bronchial arteries appeared larger than normal on the postmortem arteriograms and on microscopic examination. In the normal lung anastomoses between a preacinar pulmonary artery and a bronchial artery accompanying the same airway are uncommon. In our cases of tetralogy examination of serial sections failed to show an increase in the number of such anastomoses. The connections normally found between bronchial arteries and adjacent alveolar duct and alveolar wall arteries were, however, larger and possibly more frequent than normal. The normal intra-acinar connections between the two circulations were also seen. Examination of serial sections confirmed that the dilated arteries at the lung periphery were all dilated preacinar pulmonary arteries and not bronchial arteries or dilated anastomosing vessels between the two circulations. Thus in life the bronchial arterial supply probably made an appreciable contribution to the total pulmonary blood flow but did so through enlargement of anastomotic channels that are present in normal lung.

In these patients with tetralogy of Fallot alveolar development was also abnormal. Lung volume was $\vec{\circ}$ reduced in relation to both body surface area and age. Other pathological studies have also shown a $\vec{\omega}$ reduction in lung volume in children dying with tetralogy of Fallot. ${ }^{8}$ In life, a group of adults who had $x$ undergone a successful repair had a reduction in thoracic gas volume to $75 \%$ of the predicted value, $\overrightarrow{\vec{N}}$ and the findings were similar in those who had had $\infty$ initial palliative surgery and those who had not. ${ }^{26}$ The $\stackrel{\oplus}{\omega}$ magnitude of the reduction in thoracic gas volume in $ᄋ$ this in vivo series is similar to the magnitude of the reduction in lung volume found in the present study. In addition, postoperative lung function studies have shown only a restrictive defect, there being no evidence of obstruction to air flow. ${ }^{26}$ In the present study the alveoli and airways appeared normal macroscopically and microscopically.

Total alveolar number was reduced to a lesser extent than lung volume because the number of alveoli per unit volume of lung tissue was greater than normal. In young animals experimental reduction in blood flow is associated with a small lung composed of many small alveoli. ${ }^{27}$ These findings are encouraging because after corrective surgery the lung probably has a better chance of achieving normal alveolar development if an increase in the size of existing alveoli rather than the formation of new alveoli is required. Performing a corrective operation before the critical growth period of the lung is over presumably encourages normal alveolar development. In addition, an early repair permits greater physical activity and in normal children physical training increases total lung volume and vital capacity. ${ }^{28}$ In the lung function study referred to above the mean age at repair was 19 years and the reduction in thoracic gas volume in these patients was probably similar to what it had been in childhood. ${ }^{26}$

Thus in children with tetralogy of Fallot the $N$ pulmonary arterial circulation and the alveoli fail to develop normally. This should influence the age at $\mathrm{N}$ which the abnormality is corrected because the $\omega$ potential for growth decreases with age. In the normal lung the alveoli are formed most rapidly $\bullet$ during the first three years of life and subsequently $\mathbb{D}$ growth is by increase in size rather than number. ${ }^{29}$ In : the pulmonary circulation the ability to produce elastin decreases with age and the elastin becomes $\frac{\vec{D}}{\mathbb{D}}$ more stable, suggesting a reduction in the capacity to $\frac{\Omega}{q}$ remodel as haemodynamic conditions change. ${ }^{30}$ The $\stackrel{\mathscr{D}}{\Omega}$ extent to which the intra-acinar arteries can grow and catch up to achieve a normal size is not known. The \& thin-walled muscular arteries probably achieve a 
normal wall thickness since they have the capacity to develop medial hypertrophy in the presence of too large an aortopulmonary shunt.

In the normal lung growth and remodelling occur most rapidly during the first two years of life and repair of tetralogy of Fallot is probably best carried out during this time.

This work was supported in part by the British Heart Foundation. We wish to thank the physicians, surgeons, and pathologists of the Brompton Hospital, London; Freeman Hospital, Newcastle upon Tyne; and Deutsches Herzzentrum, Munich, West Germany.

\section{References}

${ }^{1}$ Macartney FJ, Taylor JFN, Graham GR, De Leval M, Stark J. The fate of survivors of cardiac surgery in infancy. Circulation 1980;62:80-91.

${ }^{2}$ Damman JF, Ferencz C. The significance of the pulmonary vascular bed in congenital heart disease. I-Normal lungs. II-Malformations of the heart in which there is pulmonary stenosis. Am Heart J 1956;52:7-17.

${ }^{3}$ Granston AS. Morphologic alterations of the pulmonary arteries in congenital heart disease. Proc Inst Med Chic 1958;22:116-7.

${ }^{4}$ Best PV, Heath D. Pulmonary thrombosis in cyanotic congenital heart disease without pulmonary hypertension. Journal of Pathology and Bacteriology 1958;75:281-91.

${ }^{5}$ Naeye RL. Perinatal changes in the pulmonary vascular bed with stenosis and atresia of the pulmonic valve. Am Heart J 1961;61:586-92.

6 Wagenvoort CA, Edwards JE. The pulmonary arterial tree in pulmonic atresia. Arch Pathol 1961;71:646-53.

${ }^{7}$ Wagenvoort CA, Heath D, Edwards JE. The pathology of the pulmonary vasculature. Springfield, Illinois: Charles C Thomas, 1964.

${ }^{8}$ Hislop A, Reid L. Structural changes in the pulmonary arteries and veins in tetralogy of Fallot. Br Heart $J$ 1973;35:1178-83.

9 Davies G, Reid L. Growth of the alveoli and pulmonary arteries in childhood. Thorax 1970;25:669-81.

${ }^{10}$ Hislop A, Reid L. New pathological findings in emphysema of childhood. I-Polyalveolar lobe with emphysema. Thorax 1970;25:682-90.

1 Dunnill MS. Quantitative methods in the study of pulmonary pathology. Thorax 1962;17:320-8.

${ }^{12}$ Hislop A, Reid L. Pulmonary arterial development during childhood: branching pattern and structure. Thorax 1973;28:129-35.

${ }^{13}$ Wagenvoort CA, Wagenvoort N. Pathology of pulmonary hypertension. New York: John Wiley and Sons, 1977:48.

${ }^{14}$ Brenner O. Pathology of the vessels of the pulmonary circulation. Part I. Arch Intern Med 1935;56:211-37.

${ }^{15}$ Gotsman MS, Beck W, Barnard CN, O'Donovan TG, Schrire V. Results of repair of tetralogy of Fallot. Circulation 1969;40:803-21.

${ }^{16}$ Epstein SE, Beiser D, Goldstein RE, Rosing DR, Redwood DR, Morrow AG. Hemodynamic abnormalities in response to mild and intense upright exercise following operative correction of an atrial septal defect or tetralogy of Fallot. Circulation 1973;47:1065-75.

17 Wagenvoort CA, Nauta J, Van der Schaar PJ, Weeda HWH, Wagenvoort N. Vascular changes in pulmonic stenosis and tetralogy of Fallot studied in lung biopsies. Circulation 1967;36:924-32.

${ }^{18}$ Farrar JF, Blomfield J, Reye RDK. Structure and composition of the pulmonary circulation in congenital heart disease. Journal of Pathology and Bacteriology 1965;90:97-105.

${ }^{19}$ Haworth SG, Reid L. Quantitative structural study of pulmonary circulation in the rewborn with pulmonary atresia. Thorax 1977;32:129-33.

${ }^{20}$ Haworth SG, Macartney FJ. Growth and development of the pulmonary circulation in pulmonary atresia with ventricular septal defect and major aorto-pulmonary collateral arteries. Br Heart J 1980;44:14-24.

${ }^{21}$ Meyrick B, Reid L. Hypoxia-induced structural changes in the media and adventitia of the rat hilar pulmonary artery and their regression. Am J Pathol 1980;100:15169.

${ }^{22}$ Ferencz C. The pulmonary vascular bed in tetralogy of Fallot. II-Changes following a systemic-pulmonary arterial anastomosis. Bulletin of Johns Hopkins Hospital 1960;106:100-18.

${ }^{23}$ Newfeld EA, Waldman JD, Paul MH, Muster AJ, Cole RB, Idriss F, Riker W. Pulmonary vascular disease after systemic-pulmonary arterial shunt operations. Am J Cardiol 1977;39:715-26.

${ }^{24}$ Alderson PO, Boonvisut S, McKnight RC, Hartman AF. Pulmonary perfusion abnormalities and ventilationperfusion imbalance in children after total repair of tetralogy of Fallot. Circulation 1976;53:332-7.

${ }^{25}$ Heath D, Dushane JW, Wood EH, Edwards JE. The aetiology of pulmonary thrombosis in cyanotic congenital heart disease with pulmonary stenosis. Thorax 1958;13:213-7.

${ }^{26}$ Bjarke B. Spirometric data, pulmonary ventilation and gas exchange at rest and during exercise in adult patients with tetralogy of Fallot. Scand J Respir Dis 1974;55:47-61.

${ }^{27}$ Haworth SG, McKenzie SA, Fitzpatrick ML. Alveolar development following ligation of left pulmonary artery in newborn pig: clinical relevance to unilateral pulmonary artery. Thorax 1981;36:938-43.

${ }^{28}$ Ekblom B. Effect of physical training in adolescent boys. J Appl Physiol 1969;27:350-5.

${ }^{29}$ Hislop A, Reid L. Development of the acinus in the human lung. Thorax 1974;29:90-4.

${ }^{30}$ Farrar JF, Blomfield J, Reye RDK. The structure and composition of the maturing pulmonary circulation. Journal of Pathology and Bacteriology 1965;90:83-96. 